\title{
RESEARCH PAPER IN LITERATURE OF INCREASING THICKNESS BY INCLINED TARGET
}

\author{
Elias Randjbaran ${ }^{1 \& 2}$, Rizal Zahari ${ }^{1,2 \& 3}$, Dayang Laila Majid ${ }^{1 \& 2}$, Mohamed Thariq Hameed \\ Sultan $^{1 \& 2}$, Norkhairunnisa Mazlan ${ }^{1 \& 2}$ \\ ${ }^{1}$ Department of Aerospace Engineering, Faculty of Engineering, Universiti Putra Malaysia, \\ 43400 Serdang, Selangor Darul Ehsan, Malaysia \\ ${ }^{2}$ Aerospace Manufacturing Research Centre (AMRC), Level 7, Tower Block, Faculty of \\ Engineering, 43400 UPM, Serdang, Selangor, Malaysia \\ ${ }^{3}$ Systems Engineering Department, Military Technological College, PO-Box 262 PC 111, \\ Ministry of Defence, Muscat, Sultanate of Oman
}

DOI: https://doi.org/10.29121/IJOEST.v1.i1.2017.03

\begin{abstract}
This paper displays the discoveries of the scientists about the impacts of slanted protection in ballistic effect resistance. The rule favoured stance to ascertaining the cautious layer of a composite plate is that it assembles the Line-of-Sight (LOS) thickness of the plate. Another favoured viewpoint of having slanted fortification is that it has a much higher plausibility of diverting shots than a vertical plate of tantamount thickness.
\end{abstract}

Keywords: Line-of-Sight; Inclined Armour; Inclined Impact.

Cite This Article: Elias Randjbaran, Rizal Zahari, Dayang Laila Majid, Mohamed Thariq Hameed Sultan, \& Norkhairunnisa Mazlan. (2017). RESEARCH PAPER IN LITERATURE OF INCREASING THICKNESS BY INCLINED TARGET. International Journal of Engineering Science Technologies, 1(1), 20-30. doi: 10.29121/IJOEST.v1.i1.2017.03

\section{INTRODUCTION}

In case it makes it feasible for addition the level thickness by growing the inclination while keeping the plate thickness unfaltering, it is required that one more attracted out and this way heavier covering plate to guarantee a particular range. This change of affirmation is basically proportionate to the development of locale thickness and thusly mass, and can offer no weight advantage. In this way, in protected vehicle diagram the two other rule effects of inclining have been the manner of thinking to apply slanted support [1-10].

One of these is a more successful envelopment of a particular vehicle volume by guarded layer. All around, more balanced structures have a lesser surface in regard to their volume. As in an intensely clad vehicle that surface must be secured by overpowering cautious layer, a more capable shape can incite a critical weight decreasing or a thicker defensive layer for comparable weight. Slanting the guarded layer can provoke a predominant estimation of an impeccable balanced shape [11-15].

The last effect is that of redirection, deforming and rebound of a shot. When it hits a plate under a grandiose edge, its direction might be twisted, making it go through more cautious layer - or it 
might sway off totally. Also, it can be curved, diminishing its passageway. In any case, these effects are immovably dependent on the correct defensive layer materials used and the qualities of the shot hitting it: inclining may even incite an unrivalled passageway. Formed charge warheads may disregard to invade and even detonate when striking defensive layer at a sideways edge [9-21].

The quickest edges are ordinarily seen on the frontal glacis plate, both as it is the body side well while in transit to be hit and in light of the way that there is more space to incline in the longitudinal heading of a vehicle [22-25].

The purpose behind the extended protection of a particular point at a particular customary thickness is the extended visible pathway thickness of the covering, which is the thickness along the even plane, alongside a line depicting the moving toward shot's general direction of travel. For a particular thickness of defensive layer plate, a shot must experience a more essential thickness of fortification to go through the body of vehicle when it can be slanted [26-28].

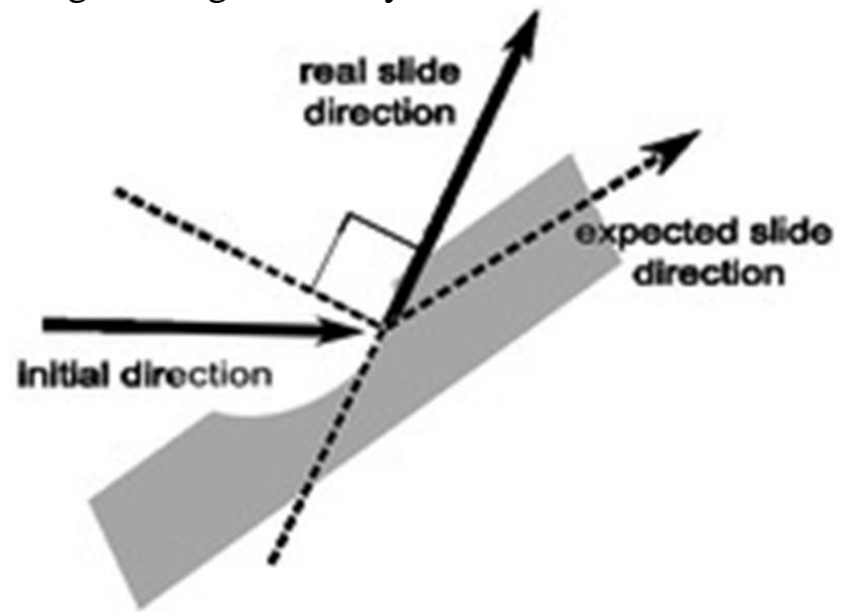

Figure 1: Real slide direction, initial direction , and expected slide direction are illustrated.

\section{PROCEDURE}

\subsection{Volume Invariant}

The inconsequential reality, which the LOS-thickness augments by computing the plate, probably is not the point of view in applying inclined protective layer in vigorously clad vehicle arrange. The clarification behind this will be this development offers no weight merit. It uses to keep up an addicted mass of a vehicle, the locale thickness could need to remain comparable and these recommends the LOS-thickness would like this manner and need to remain relentless while the slope angle goes up that deducing again the usual thickness reduces. Therefore, to dodge extending the largeness of the vehicle, plates need to get moderately thinner while their inclination fabricates a technique similar to do shearing the mass [29-32].

Inclined covering gives extended protection to fortified doing combating vehicles through two basic frameworks. The inclining may diminish the surface to volume extent and along these lines contemplate either a lesser relative mass for a particular volume or more security for a particular weight and the most fundamental rely on upon the route that is to fulfil a particular 
mass of fortification must encase a particular protection level a particular volume. Therein, the strike was correspondingly likely from all headings; the ideal shape would be a hover; since level attack is in reality not strange the ideal transforms into an oblate spheroid. Figuring level plates or twisting cast guarded layer licenses organizers to approach these principles. For down to earth reasons this framework is consistently associated on the front of the vehicle, where there is satisfactory space to slant and a noteworthy part of the defensive layer is concentrated, on the assumption. Thus, it can unidirectional frontal attack is more than likely. An essential specimen, for instance, it can be probably found in the casing arrangement of the M1 Abram, is starting now an modern design that is by now and again associated [33-35].

The second instrument is that shots hitting slanted shield will most likely be dodged rebound or break on impact. Display day weapon and assurance advancement have through and through diminished this second preferred standpoint which at first was the essential manner of thinking slanted fortification was intertwined into vehicle arrange in the Second World War [33-37].

a] incident deflection
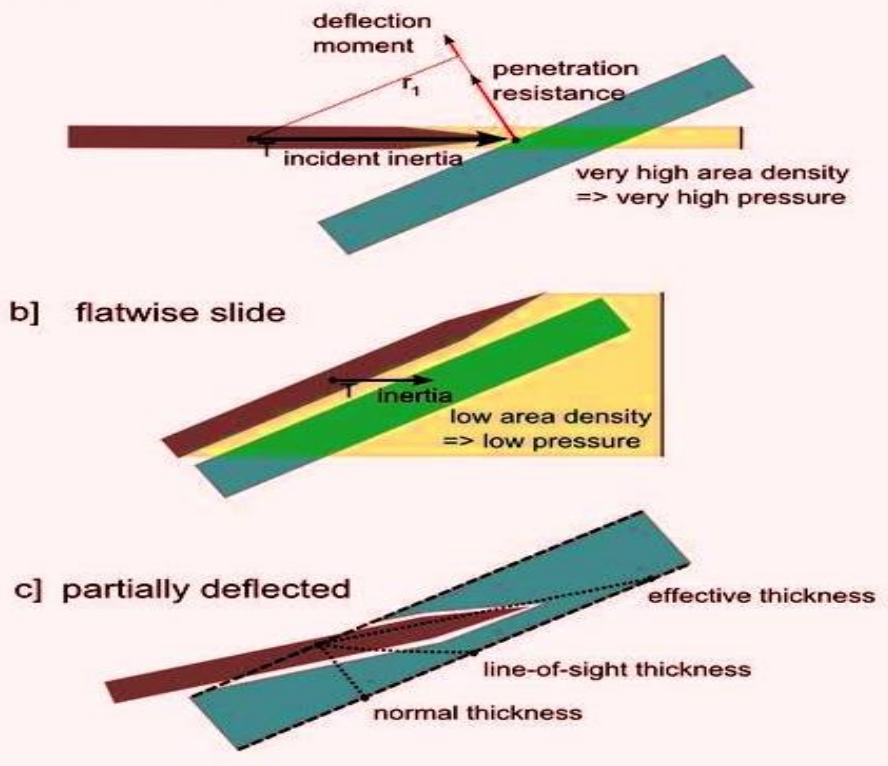

d] divergence of defflection

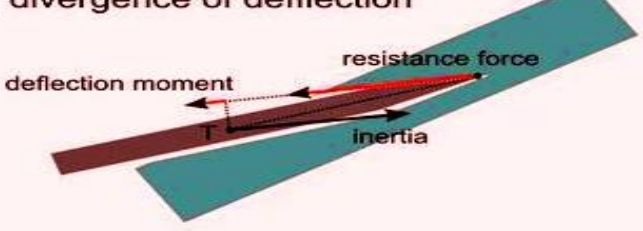

e] bent in effect

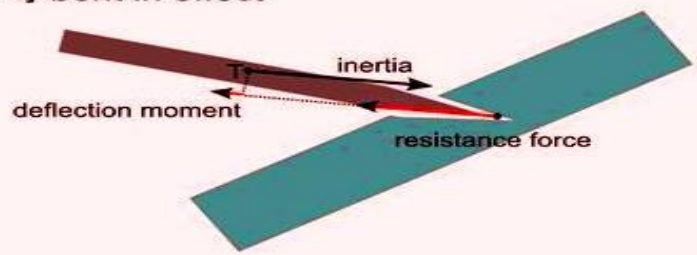

Figure 2: Outline of some conceivable impacts that can happen when a shot effect inclined reinforcement. 


\subsection{The Cosine Runs the Show}

Despite the way that the extended security to a point, which is given by figuring a particular shell denture with a particular sweetheart heaviness understanding an increased noticeable LOSthickness. Then, there is no idea in covering vehicle aim, it is of impressive centrality during picking the level of avowal of a made vehicle. The LOS-thickness for a vehicle in a level stead can be set up by a sensible formula, applying the cosine guides: it is comparison to the cautious layer's fundamental frequency thickness assigned by the cosine of the support's dip from oppositeness to the guess's travel (thought to be in the level plane) [38-41]:

Where;

$$
\mathrm{T}_{\mathrm{L}}=\mathrm{T}_{\mathrm{N}} / \cos (\alpha)
$$

- $\alpha$ : Angle of the sloped armour plate from the vertical

- $\mathrm{T}_{\mathrm{N}}$ : Normal thickness

- $\mathrm{T}_{\mathrm{L}}$ : Line of sight thickness

For instance, covering inclined sixty arc degree over from the upright presents, which is uniformly to a shot voyaging a detectable pathway heaviness twofold the defensive bed's commonplace thickness, as the cosine of 60 degrees is 0.50 . Soon after covering breadth or equivalency moved consistent defensive layer values for heavily clad battling vehicles are particular without the grade of the buckler, the consider gave overall brings account this effect of the leaning, while when the heed is in the secret plan of "x building block at y degrees", the effects of the list are not considered [42-48].

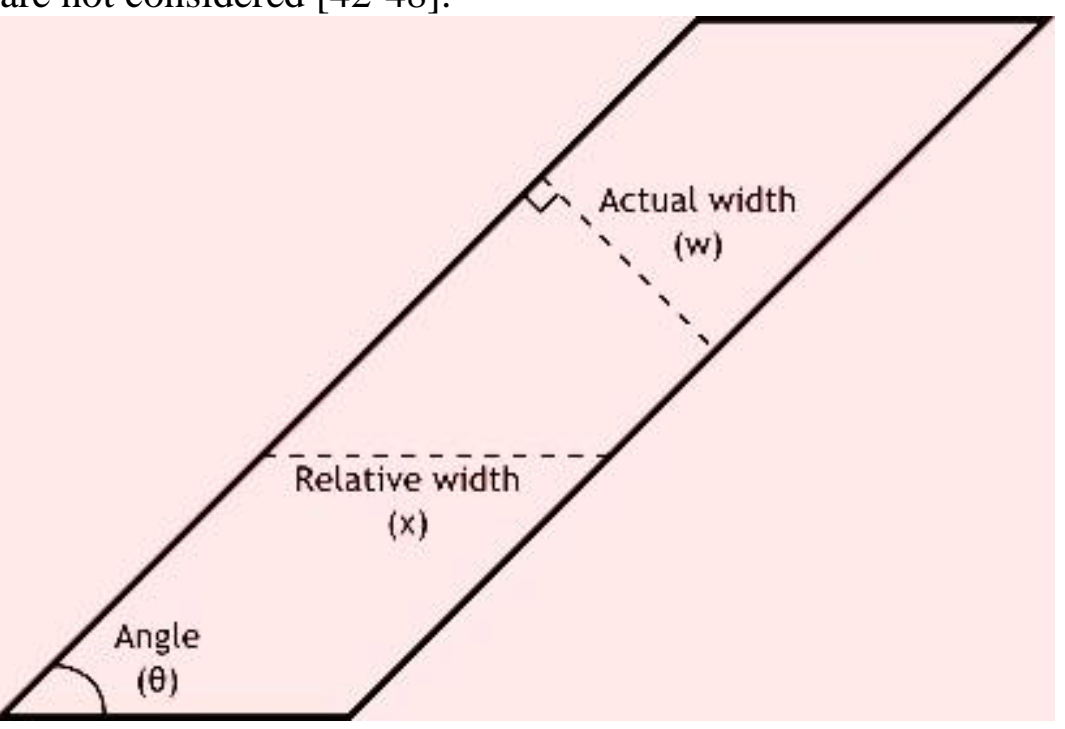

Figure 3: Exhibition of how the relative protective layer thickness is more noteworthy than the genuine reinforcement thickness of a slanted defensive layer plate.

\subsection{Avoidance}

The inclining protective layer can grow security by a part, for instance, shattering of a delicate engine essentialness impactor or a redirection of that impactor a long way from the surface ordinary, regardless of the way that the range thickness remains predictable. These influences are most grounded when the shot has a low preeminent weight and is short in regard to its width. 
Cautious layer entering shells of the World War II, without a doubt those of the early years, had these qualities and slanted fortification was as needs be genuinely capable in that period. In any case, in the sixties, long-bar impactors were exhibited, shots that are both uncommonly drawn out and amazingly thick in mass. Hitting slanted thick homogeneous plates such a long-bar impactor will, in the wake of beginning invasion in the covering's LOS thickness, bend toward the guarded layer's common thickness and carry away with a length between the defensive layer's LOS and normal thicknesses. Furthermore, the turned impactor has a tendency to go about as an injection of an unlimited expansiveness and this expands whatever is left of the security, making it crash and burn all the more viably. If these last effects happen solidly - for bleeding edge impactors, this is routinely the case for a grade some place around 55 to 65 degrees - better affirmation can be particular by vertically mounted cautious layer of comparative zone thickness. Another headway lessening the importance of the control of a slanted defensive layer has been the presentation of pottery support in the seventies. At any particular district thickness, an aesthetic defensive layer is in like manner best when mounted more vertically, as keeping up comparable locale thickness requires the shield be reduced as it is slanted and the earth splits earlier as a consequence of its diminished conventional thickness [4551].

The inclined protective layer can similarly make shots rebound, be that as it may, this ponder is significantly more jumbled and 'in the not too distant past not totally obvious. High shaft thickness, influence speed, and length-to-expansiveness extent are parts that add to a high essential rebound edge (the time when rebound is depended upon to onset) for a long post shot [49-55]; however, remarkable formulae may foresee particular fundamental rebound plots for the comparable condition.

\section{RESULTS AND DISCUSSIONS}

How an area brought on by shot impact manufactures the effective scene edge (cut down grade affect). Framework of some possible effects that can happen when shot impacts slanted support [54-59].

Particularly, direct physical can be model of the grade affect. Dynamic imperativeness devoured by guarded layer is relating to the square of the sine of edge (maximum for $90^{\circ}$ ). Contorting of target and contact are expelled [58-60].

The direct of a certifiable shot and the shield plate it hits depends on upon various effects and instruments, including their material structure and continuum mechanics which are to a great degree difficult to anticipate. Using only two or three basic measures will likewise not achieve a model that is a not too bad depiction of the full extent of possible outcomes. Regardless, in various conditions, a vast segment of these components have only an irrelevant effect while two or three of them lead the condition. In this way, an outstandingly enhanced model can be made giving a general thought and appreciation of the key physical norms behind these parts of slanted protective layer arrange [61-65].

If the shot ventures brisk, and as needs be is in a state of hypervelocity, the nature of the cautious layer material gets the opportunity to be inconsequential - as by the impact both shot and the 
defensive layer will condense and bear on like fluids - and simply its domain thickness is a key variable. In this confining case, the shot after the hit continues penetrating until it has stopped trading its drive to the goal matter. In this flawless case just vitality, extend cross range; thickness, and LOS-thickness are imperative. The condition of the penetrating metal fly brought on by the impact of the formed charge of HEAT ammunition outlines a not too bad figure of this great. In this way, if the fact of the matter is not exceptionally phenomenal, and the shot is to a great degree thick and snappy, inclining has little effect and no relevant redirection happens [6466].

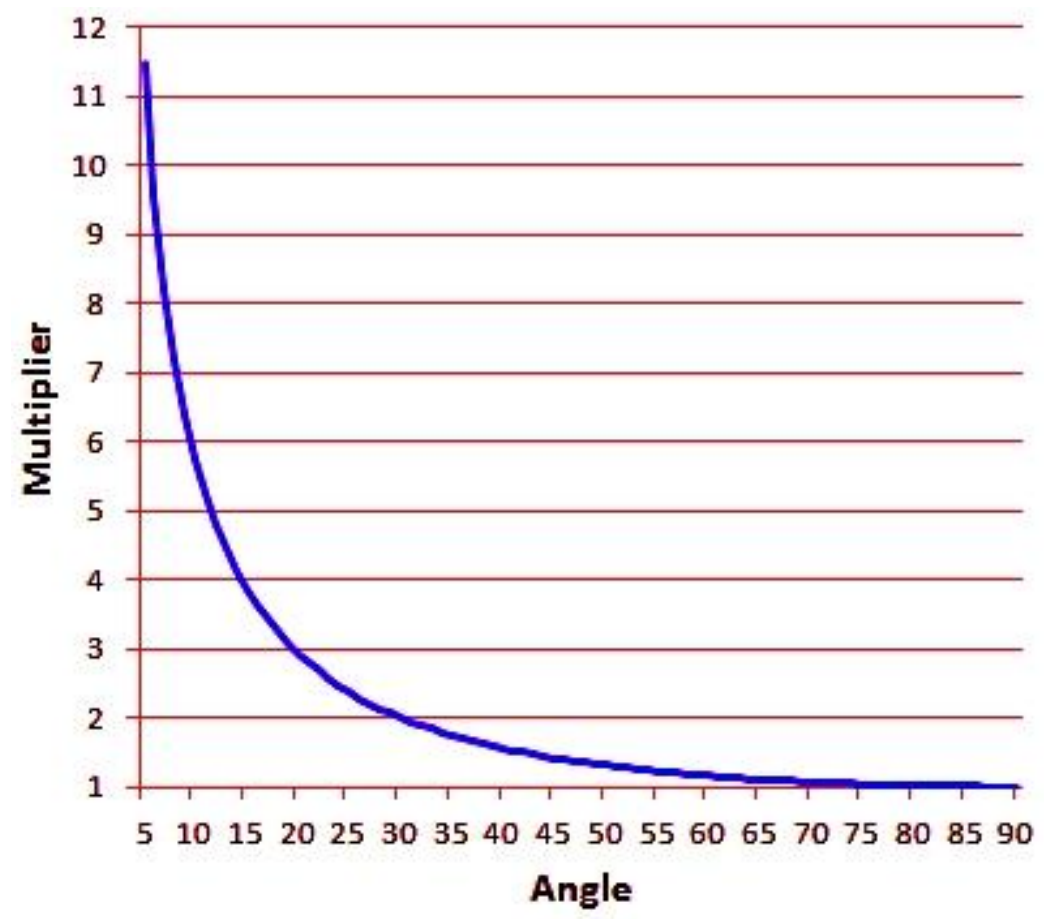

Figure 4: Protective layer multiplier from five to 90 degrees.

However, the modify obviously could be in every way that really matters isolated into a deceleration part, when the shot is halted while shifting in an orientation inverse to the plate and will pass alongside the plate resulting to having been occupied at a nation of about $\alpha$ and a strategy of adaptable animating, when the shot stimulates out of the plate velocity alongside the plate is taken into consideration as invariant because of superfluous pounding. On this way, the high-quality essentialness collected by the plate can be figured from the deceleration time of the effect occasion:

Where

$$
\mathrm{E}_{\mathrm{d}} / \mathrm{E}_{\mathrm{k}}=\sin ^{2}(\alpha)
$$

- $\mathrm{E}_{\mathrm{d}}$ : Energy transferred to the target

- $\mathrm{E}_{\mathrm{k}}$ : Incident kinetic energy of projectile

- $\alpha$ : Angle of the sloped armour plate from the projectile's initial direction

Under the doubt that solitary adaptable winding happens and that the goal is solid, while insulting pounding, it is definitely not hard to figure the degree of essentialness devoured by the target in case it is hit by shot, which, if they also are rejected additionally puzzling redirection 
impacts, delayed consequence rebounds off (flexible case) alternately slides along with (romanticized plastic case) those shield plates. [23-28, 39-45].

\section{CONCLUSIONS}

The slanting protective layer can fabricate confirmation by an instrument, thickness of the plate disengaged by the co-sin of the point from impact course. Alongside these lines, the case for the occasion of a $100 \mathrm{~mm}$ piece of plate at a $20^{\circ}$ inclination from vertical with the shell course being parallel to the ground: $100 / \cos (20)=100 / 0.9397=106.42$. The rational eventual outcome of this is a gun fit for entering a composite plate without striking slanted covering may not be fit for penetrating a composite plate which has less defensive layer, yet is inclined. In the hindrance, use inclines found on the scene to incite incline [65-69].

\section{REFERENCES}

[1] Randjbaran, E., Zahari, R., Majid, D. L., Jalil, N. A. A., Vaghei, R., \& Ahmadi, R. (2013) An Experimental Investigation of the Effects of Stacking Sequence on Hybrid Composite Materials Response to Open-Hole Compression Strength. MATRIX Academic International Online Journal of Engineering and Technology, 1(2), 1-6.

[2] Randjbaran, E., Zahari, R., Majid, D. L., Jalil, N. A. A., Vaghei, R., \& Ahmadi, R. (2013) The Effects of Stacking Sequence Layers of Hybrid Composite Materials in Energy Absorption under the High Velocity Ballistic Impact Conditions: An Experimental Investigation. MATRIX Academic International Online Journal of Engineering and Technology, 1(2), 30-37.

[3] Randjbaran, E., Zahari, R., Majid, D. L., Jalil, N. A. A., \& Vaghei, R. (2013) Effects of Stacking Sequence on Compression Response Testing of Carbon Fibre and Hybrids: FibrousGlass/Carbon/Kevlar/ Epoxy Composite Plates. MATRIX Academic International Online Journal of Engineering and Technology, 2(1), 13-17.

[4] Randjbaran, E., Zahari, R., Majid, D. L., Jalil, N. A., Vaghei, R., \& Ahmadi, R. (2013). The effects of stacking sequence layers of six layers composite materials in ballistic energy absorption. International Journal of Material Science Innovations, 1(6), 293-305.

[5] Randjbaran, E., Zahari, R., Majid, D. L., Jalil, N. A. A., Vaghei, R., \& Ahmadi, R. (2014). Experimental Study of the Influence of Stacking Order of the Fibrous Layers on Laminated Hybrid Composite Plates Subjected to Compression Loading. Journal of Science and Engineering, 4(1), 01-08.

[6] Randjbaran, E., Zahari, R., Abdul Jalil, N. A., \& Abang Abdul Majid, D. L. (2014). Hybrid Composite Laminates Reinforced with Kevlar/Carbon/Glass Woven Fabrics for Ballistic Impact Testing. The Scientific World Journal, doi:10.1155/2014/413753.

[7] Ghaemi, F., Amiri, A., \& Yunus, R. (2014). Methods for coating solid-phase micro extraction fibres with carbon nanotubes. TrAC Trends in Analytical Chemistry, 59, 133-143.

[8] Gao, S. J., Shi, Z., Zhang, W. B., Zhang, F., \& Jin, J. (2014). Photo induced super wetting singleWalled Carbon Nanotube/TiO2 Ultrathin Network Films for Ultrafast Separation of Oil-in-Water Emulsions. ACS nano, 8(6), 6344-6352.

[9] Gernand, J. M., \& Casman, E. A. (2014). A Meta-Analysis of Carbon Nanotube Pulmonary Toxicity Studies-How Physical Dimensions and Impurities Affect the Toxicity of Carbon Nanotubes. Risk Analysis, 34(3), 583-597.

[10] Siddique, R., \& Mehta, A. (2014). Effect of carbon nanotubes on properties of cement mortars. Construction and Building Materials, 50, 116-129. 
[11] Cogan, N. M., Bowerman, C. J., Nogaj, L. J., Nilsson, B. L., \& Krauss, T. D. (2014). Selective suspension of single-walled carbon nanotubes using $\beta$-sheet polypeptides. The Journal of Physical Chemistry C, 118(11), 5935-5944.

[12] Xu, S., Liu, J., \& Li, Q. (2015). Mechanical properties and microstructure of multi-walled carbon nanotube-reinforced cement paste. Construction and Building Materials, 76, 16-23.

[13] Yaghoobi, H., \& Fereidoon, A. (2014). Mechanical and thermal buckling analysis of functionally graded plates resting on elastic foundations: Assessments of a simple refined nth-order shear deformation theory. Composites Part B: Engineering, 62, 54-64.

[14] Jensen, B. D., Wise, K. E., \& Odegard, G. M. (2015). Simulation of the Elastic and Ultimate Tensile Properties of Diamond, Graphene, Carbon Nanotubes, and Amorphous Carbon Using a Revised ReaxFF Parameterization. The Journal of Physical Chemistry A.

[15] Georgakilas, V., Perman, J. A., Tucek, J., \& Zboril, R. (2015). Broad Family of Carbon Nano allotropes: Classification, Chemistry, and Applications of Fullerenes, Carbon Dots, Nanotubes, Graphene, Nano diamonds, and Combined Superstructures. Chemical reviews.

[16] Torres, L. E. F., Roche, S., \& Charlier, J. C. (2014). Introduction to graphene-based nanomaterial's: from electronic structure to quantum transport. Cambridge University Press. Shen, H. S. (2013). Thermal postbuckling of shear deformable FGM cylindrical shells surrounded by an elastic medium. Journal of Engineering Mechanics, 139(8), 979-991.

[17] Mishra, R., Militky, J., Baheti, V., Huang, J., Kale, B., Venkataraman, M.\& Wang, Y. (2014). The production, characterization and applications of nanoparticles in the textile industry. Textile Progress, 46(2), 133-226.

[18] Yakobson, B. I., \& Avouris, P. (2001). Mechanical properties of carbon nanotubes. In Carbon nanotubes (pp. 287-327). Springer Berlin Heidelberg.

[19] Randjbaran, E., Zahari, R., Majid, D. L., Sultan, MTH., Mazlan, N. (2016) Effects of Sloped Armour in Ballistic Impact Resistance - A Review Paper. MATRIX Academic International Online Journal of Engineering and Technology, 2(4), 19-26. http://maioj.org/data/documents/oct2016/101603.pdf

[20] Randjbaran, E., Zahari, R., Majid, D. L., Sultan, MTH., Mazlan, N. (2016) Reasons of Adding Carbon Nanotubes into Composite Systems. Технічні вісті Technical News, 2(44), 31-37. http://technicalnews.net.ua/library/2016/31.pdf

[21] Gautieri, A., Vesentini, S., Redaelli, A., \& Buehler, M. J. (2011). Hierarchical structure and nanomechanics of collagen microfibrils from the atomistic scale up. Nano letters, 11(2), 757-766.

[22] Zhang, A. Y. (2014, August). Research on the Properties and Defects of Carbon Nanotubes. In Advanced Materials Research (Vol. 971, pp. 157-160).

[23] Randjbaran, E., Zahari, R., Majid, D. L., Sultan, MTH., Mazlan, N. (2016) Reasons of Adding Carbon Nanotubes into Composite Systems. Технічні вісті Technical News, 2(44), 31-37. http://technicalnews.net.ua/library/2016/31.pdf

[24] Dasa, R., Hamida, S. B. A., Alia, M. E., Ramakrishnab, S., \& Yongzhib, W. (2015). Carbon Nanotubes Characterization by X-ray Powder Diffraction-A. Current Nanoscience, 11, 000-000.

[25] Pathak, S., Mohan, N., Decolvenaere, E., Needleman, A., Bedewy, M., Hart, A. J., \& Greer, J. R. (2013). Local relative density modulates failure and strength in vertically aligned carbon nanotubes. ACS nano, 7(10), 8593-8604.

[26] Luhyna, N., \& Inam, F. (2012). Carbon Nanotubes for Epoxy Nanocomposites: A Review on Recent Developments. Advanced Composite Materials and Technologies for Aerospace Applications, 80 .

[27] Varsakelis, C., \& Papalexandris, M. V. (2011). Numerical study of unsteady shear, and gravitydriven granular flows. Bulletin of the American Physical Society, 56.

[28] Kuwar, M., \& Kamal, S. (2013). Molecular Dynamics Simulation Study of Novel Properties of Defect Full Single Walled Carbon Nanotubes. International Journal of Application or Innovation in Engineering \& Management (IJAIEM), 2 (2), 77-81. 
[29] Yazdchi, K., Salehi, M., \& Shokrieh, M. M. (2008). EFFECTIVE STRUCTURAL PARAMETERS OF SINGLE-WALLED CARBON NANOTUBES. The European Society for Composite Materials, 1-10 http://www.escm.eu.org/docs/eccm13/1410.pdf

[30] Zang, J. L., Yuan, Q., Wang, F. C., \& Zhao, Y. P. (2009). A comparative study of Young's modulus of single-walled carbon nanotube by CPMD, MD and first principle simulations. Computational Materials Science, 46(3), 621-625.

[31] 臓金良, 袁泉子, 王奉超, \& 赵亚溥. (2009). A comparative study of Young's modulus of singlewalled carbon nanotube by CPMD, MD, and first principle simulations.

[32] Liu, L., Gao, J., Guo, X., \& Zhao, J. (2013). Electromechanical properties of zigzag-shaped carbon nanotubes. Phys. Chem. Chem. Phys., 15(40), 17134-17141.

[33] Hoffman, J. D. (2011). Ab Initio Modeling of the Mechanical Properties of Carbon Nanotubes Using Gaussian. In 52nd AIAA/ASME/ASCE/AHS/ASC Structures, Structural Dynamics and Materials Conference 19th AIAA/ASME/AHS Adaptive Structures Conference 13t (p. 1919).

[34] Abdellatif, S., \& Hédi, H. (2011). Prediction of the elastic properties of single walled carbon nanotube reinforced polymers: a comparative study of several micromechanical models. INTECH Open Access Publisher.

[35] Selmi, A., Friebel, C., Doghri, I., \& Hassis, H. (2007). Prediction of the elastic properties of single walled carbon nanotube reinforced polymers: a comparative study of several micromechanical models. Composites Science and Technology, 67(10), 2071-2084.

[36] Shokrieh, M. M., Saeedi, A., \& Chitsazzadeh, M. (2013). Mechanical properties of multi-walled carbon nanotube/polyester nanocomposites. Journal of Nanostructure in Chemistry, 3(1), 1-5.

[37] Ruoff, R. S., Qian, D., \& Liu, W. K. (2003). Mechanical properties of carbon nanotubes: theoretical predictions and experimental measurements. Comptes Rendus Physique, 4(9), 993 1008 .

[38] Yakobson, B. I., \& Avouris, P. (2001). Mechanical properties of carbon nanotubes. In Carbon nanotubes (pp. 287-327). Springer Berlin Heidelberg.

[39] Cheng, H. C., Liu, Y. L., Hsu, Y. C., \& Chen, W. H. (2009). Atomistic-continuum modeling for mechanical properties of single-walled carbon nanotubes.International Journal of Solids and Structures, 46(7), 1695-1704.

[40] M.-F. Yu et al. (2000). Strength and Breaking Mechanism of Multiwalled Carbon Nanotubes Under Tensile Load. Science 287 (5453): 637-40.

[41] R. S. Ruoff et al. (1993). Radial deformation of carbon nanotubes by van der Waals forces. Nature 364 (6437): 514.

[42] Palaci et al. (2005). Radial Elasticity of Multiwalled Carbon Nanotubes. Physical Review Letters 94: 175502.

[43] M.-F. Yu et al. (2000). Investigation of the Radial Deformability of Individual Carbon Nanotubes under Controlled Indentation Force. Physical Review Letters 85 (7): 1456-9.

[44] Y.H.Yang et al. (2011). Radial elasticity of single-walled carbon nanotube measured by atomic force microscopy. Applied Physics Letters 98: 041901.

[45] M. Minary-Jolandan, M.-F. Yu (2008). Reversible radial deformation up to the complete flattening of carbon nanotubes in nanoindentation. Journal of Applied Physics 103: 073516.

[46] Randjbaran, E., Zahari, R., Majid, D. L., Jalil, N. A., Vaghei, R., \& Ahmadi, R. (2013). The effects of stacking sequence layers of hybrid composite materials in energy absorption under the high velocity ballistic impact conditions: an experimental investigation. Journal of Material Sciences \& Engineering, 2(4), 1-8.

[47] Randjbaran, E., Zahari, R., \& Vaghei, R. (2014). Scanning Electron Microscopy Interpretation In Carbon Nanotubes Composite Materials After Postbuckling-Review Paper. MATRIX Academic International Online Journal of Engineering and Technology, 2(2), 1-6.

[48] Saghravani, S. R., Mustapha, S. A., Ibrahim, S., Zawawi, M., Azwan, M., \& Randjbaran, E. (2010). Simulation of phosphorus movement in unconfined aquifer by means of visual MODFLOW. Journal of Computer Science, 6(4), 446-449. 
[49] Randjbaran, E., Zahari, R., Vaghei, R., \& Karamizadeh, F. (2015). A Review Paper on Comparison of Numerical Techniques for Finding Approximate Solutions to Boundary Value Problems on Post-Buckling in Functionally Graded Materials. Trends Journal of Sciences Research, 1 (1), 1-6.

[50] Randjbaran, E., Zahari, R., \& Vaghei, R. (2014). Computing Simulation of Post-buckling in Functionally Graded Materials-A Review. TELKOMNIKA Indonesian Journal of Electrical Engineering, 12(12), 8344-8348.

[51] Hemat, M. G., \& Heng, C. S. (2012). Interplay of Language Policy, Ethnic Identity and National Identity in Five Different Linguistic Settings. International Journal of Applied Linguistics and English Literature, 1(7), 1-7.

[52] Granhemat, M., Heng, C. S., \& Abdullah, N. (2014). USING THE MULTI-ETHNIC GROUP MEASURE AS AN INDICATOR OF MALAYSIAN ETHNIC IDENTITIES. Malaysian Journal of Languages and Linguistics, 3(1), 31-37.

[53] Granhemat, M., Abdullah, A. N., Heng, C. S., \& Tan, H. (2015). The Influence of Gender and Ethnicity on the Choice of Language in the Transaction Domain of Language Use: The Case of Undergraduates. International Journal of Applied Linguistics and English Literature, 4(5), 249254.

[54] Tahmoorespour, R., Rezvani, M., Safari, M., \& Randjbaran, E. (2015). Oil Price Fluctuations and Industry Stock Returns. Middle-East Journal of Scientific Research, 23(9), 2035-2050.

[55] TAHMOORESPOUR, R., Mina, A. A., \& RANDJBARAN, E. The Impact of Capital Structure on Stock Returns: International Evidence. Hyperion Economic Journal, 1(3), 56-78

[56] Tahmoorespour, R. R., \& Safari, M. M. and Randjbaran, E.(2015). Oil Price Fluctuations and Industry Stock Returns. Bulletin of Energy Economics http://www. tesdo. org/JournalDetail. aspx, 1.

[57] Karamizadeh, F. et al (2015). Face Recognition by Implying Illumination Techniques-A Review Paper. Journal of Science and Engineering; Vol, 6(01), 001-007. http://www.oricpub.com/SE0060085.pdf

[58] Nazari, A., \& Riahi, S. (2015). Corrigendum to "Microstructural, thermal, physical and mechanical behavior of the self compacting concrete containing SiO 2 nanoparticles"[Mater. Sci. Eng. A 527 (29)(2010) 7663-7672]. Materials Science and Engineering: A, 642, 316.

[59] Givi, A. N., Rashid, S. A., Aziz, F. N. A., \& Salleh, M. A. M. (2013). Influence of 15 and 80 nano-SiO2 particles addition on mechanical and physical properties of ternary blended concrete incorporating rice husk ash. Journal of Experimental Nanoscience, 8(1), 1-18.

[60] Givi, A. N., Rashid, S. A., Aziz, F. N. A., \& Salleh, M. A. M. (2011). The effects of lime solution on the properties of $\mathrm{SiO} 2$ nanoparticles binary blended concrete. Composites Part B: Engineering, 42(3), 562-569.

[61] Sanjayan, J. G., Nazari, A., Chen, L., \& Nguyen, G. H. (2015). Physical and mechanical properties of lightweight aerated geopolymer. Construction and Building Materials, 79, 236-244.

[62] Rohazrin, A. R., Shakrine, M. A., Rizal, Z., \& Tarmizi, A. M. (2015). Effects of different crosssection shapes on bending and weight of harvesting pole by using finite element analysis. J. Trop. Agric. and Fd. Sc, 43(2), 191-201.

[63] Haery, H. A., Kim, H. S., Zahari, R., \& Amini, E. (2014). Tensile strength of notched carbon/glass/epoxy hybrid composite laminates before and after fatigue loading| NOVA. The University of Newcastle's Digital Repository.

[64] Rasooliyazdi, E., Zahari, R. B., Ghadianlou, A., Farhaninejad, A., Sahari, B. B., Aziz, F. A., \& Jamali, H. (2014). Crashworthiness Design of Vehicle Side Door Beam Based on Elliptical Geometry Modification Using Multi-Objective Optimization. International Review of Mechanical Engineering (IREME), 8(1), 28-35.

[65] Lim, K. T., Zahari, R., Mustapha, F., Sultan, H., \& Thariq, M. (2014). Experimental assessment of collapse behavior and energy absorption of composite and hybrid composite square tube subjected to oblique loads. The International Journal of Engineering and Science, 3(3), 13-29. 
[66] Sultan, M. T. H., Basri, S., Rafie, A. S. M., Yidris, N., Mustapha, F., Zahari, R., \& Ajir, M. R. (2014, July). Impact Damage Analysis for Glass Reinforced Epoxy Laminated Plates Using Single Stage Gas Gun. In Applied Mechanics and Materials (Vol. 564, pp. 382-387).

[67] Rasid, Z. A., Zahari, R., \& Ayob, A. (2014). The Instability Improvement of the Symmetric Angle-Ply and Cross-Ply Composite Plates with Shape Memory Alloy Using Finite Element Method. Advances in Mechanical Engineering, 6, 632825.

[68] Rasid, Z. A., Zahari, R., \& Ayob, A. B. (2014, July). The Instability Improvement of the Shape Memory Alloy Composite Plates Subjected to In-Plane Parabolic Temperature Distribution. In Applied Mechanics and Materials (Vol. 554, pp. 32-36).

[69] Zakikhani, P., Zahari, R., Sultan, M. T. H., \& Majid, D. L. (2014). Bamboo fibre extraction and its reinforced polymer composite material. Int J Chem, Mater Sci Eng, 8, 54-7.

*Corresponding author.

E-mail address: Elias@gmx.co.uk 